\title{
College Students’ Spirituality Growth through Buddhist Sutra Adaptation Experiences*
}

\author{
De-Yin Shih, Yu-Mei Tsai \\ Tzu Chi University of Science and Technology, Hualien, Taiwan
}

\begin{abstract}
The paper analyzes a religion-based college's spiritual education through Buddhist sutra adaptation (BSA) experiences to explore the students' perceptions of good, filial piety, and environmental ethics, as well as their behavioral modifications, accordingly. The BSA is an artistic presentation of singing and signing in the Tzu Chi Missions for moral reflection on desire, anger, and ignorance. The participating students are interviewed and observed for their after-school participation of BSA experiences, and in the context of humanities course performance. This paper intends to highlight a special form of moral education through BSA experiences.
\end{abstract}

Keywords: moral education, spirituality education, Buddhist sutra adaptation (BSA), Water Repentance

\section{Introduction}

Morality cannot be taught but modeled. It is a popularly acknowledged approach to moral education, but it is rarely documented in higher education. Following Kohlberg's (1958) theory of development or moral reasoning, college students are expected to go beyond the pre-conventional stages or even conventional stages. However, more shocking disasters hit the world, including the September 11 terror attack in the United States (U.S.), the Haitian earthquake, and the Japanese tsunami on March 11. If we trace the cause of both natural and human disasters, we would find the culprit to be the human mind. The early proclamation of sustainable development by United Nations Educational, Scientific, and Cultural Organization-United Nations Environment Programme (UNESCO-UNEP) in 1992 did not prompt effective recognition because of the lack of individual moral sensibility and consciousness (Mische, 1994). Hackney (2010) proposed penitence as positive character strengths by explicating the works by Palazzini (1962), Rahner (1969), and Harrison (1987) to describe penitence as a dispositional tendency to feel sorrow when one has sinned, to turn again toward God, and to seek atonement and make reparation (p. 202). Therefore, penitence is seen as a virtue approaching Christ-likeness.

With Buddhist assumptions of the inborn nature of Buddha and the naturalness of good life of all sentient beings, penitence has two levels of spirituality to reach enlightenment—one is to acknowledge wrong-doing and the other is to eliminate evil. Deeply concerned with the aggressive harm caused by natural disasters and

\footnotetext{
* Acknowledgement: This paper had been partially presented at the 15th World Conference on Education, Kaohsiung, Taiwan on December 31, 2012. The authors were then invited to present the paper at the 24th SPC (Saint Paul Chartres) Educators' Congress and 9th International SPC Educators' Congress, Manila, the Philippines on May 10, 2013.

De-Yin Shih, B.A., lecturer, Holistic Education Center, Tzu Chi University of Science and Technology.

Yu-Mei Tsai, Dr., associate professor, Holistic Education Center, Tzu Chi University of Science and Technology.
} 
human conflicts worldwide, the Buddhist Compassion Relief Tzu Chi Foundation ${ }^{1}$ (Tzu Chi Foundation, 2011) launched a social reform of repentance over the island of Taiwan in August, resorting to a performance arts presentation of sign language opera entitled Dharma as Water: Great Repentance based on the Buddhist scripture Compassionate Samadhi Water Repentance. The rationale is to lead the masses to sing the sincere regret of wrong-doing through theatrical sketches, song, and sign language. The stage adaptation comprises five acts: the prelude, the obstacle of affliction, the obstacle of unwholesome action, the obstacle of karmic retribution, and finale. It incorporates the multiple performing arts elements of Taiwanese opera, Chinese opera, modern dance, drama, and signing.

With more than 60 professional performing artists on the stage, over 30,000 Tzu Chi volunteers had organized into different venues to present the sutra adaptation. All participants had to pledge to be vegetarians for 108 days to show their sincerity and willingness to repent. Later in March 2012, the Tzu Chi Education Mission organized a second sutra adaptation of Water Repentance involving 1,008 students and staff from Tzu Chi University and the Tzu Chi College of Technology (TCCT), along with the professional performing artists on the stage. This paper intends to provide a contextual description of how the TCCT student participants reflected on their experiences of Buddhist sutra adaptation (BSA) and how they perceive their behavior modifications.

\section{Literature Review}

\section{Spirituality}

Before the millennium, Zinnbauer, Pargament, and Scott (1999) suggested a dynamic presentation of religion and spirituality "in motion" within the larger context of personal, social, and situational forces to capture the search for the sacredness at the heart of religion, instead of polarizing the constructs. Smith (1994) cited the construct of spirituality by Elkins et al. (1988) as encompassing the humanistic perspective with four manifestations - feeling meaningful, developing relationships, being touched by the pain of others, and feeling sacredness in all forms of life. Smith and Zhang (2011) surveyed retreatants to suggest that being religious was significantly more essential than being spiritual to benefit more for the meanings of religiousness and spirituality, although the spiritual but less religious were more likely to benefit from insight regarding relationships and the self.

Tisdell (2007) called for attention to address spirituality in higher education integrated into the concerns of diversity, equity, and cultural issues, referring to Laura Rendon's (2000) speech to encourage a new framework in higher education to bridge the inner and outer knowing, namely: imagination, rationality, and a marriage between rationality and spirituality. An early paper by Tisdell (2006) quoted Rabbi Michael Lerner's (2000) explanation of "emancipatory spirituality" and "reactionary spirituality" on a sense of love and respect within different cultures and traditions. Tisdell (2006) also cited the discussions by Fowler (1981) and Parks (2000) on the imagination in spiritual experiences and knowledge construction to emphasize the cultural dimension of imagination in the forms of music, art, poetry, language, and different forms of communication and symbol-making, touching off memory connecting to spirituality. Palmer (1995) indicated a sense of unity with people and objects to achieve devotion to process in the mundane (p. 104), so that the experiences could be enlightened and spiritual and in the moment.

\footnotetext{
${ }^{1}$ The Buddhist Compassion Relief Tzu Chi Foundation, a non-profit organization in Taiwan, was founded by Dharma Master Cheng Yen, and has the four Tzu Chi missions — charity, medicine, education, and culture — to promote humanitarianism through worldwide services over 90 countries on the five continents.
} 
The similar spiritual awareness of caring and love was addressed in a graduate course of psychology through the sharing of lived experiences to show that the reflections shared by students and teachers facilitate spiritual experience (Miller \& Athan, 2007). Consequently, the classroom atmosphere encourages contemplation and support in which failure transformed into opportunity (p. 32). To promote spiritual qualities in school curricula, the arts must become a follow-up course to religious education, because a substantial amount of music incorporates religious themes to express the religious experience, or large human questions of good and evil, sin and suffering, freedom and responsibility. To realms of human experience, feeling and value that lie beyond everyday concerns, in that the form of musical works stimulates spiritual significance by insights and experiences transcending the purely empirical (Carr, 2008, p. 23). This echoed Zajonc (2006) quoating Parker Palmer's speech (1993) regarding the connection between epistemology and ethics to call for a contemplative inquiry, to transform knowledge into an epistemology of intimacy and participation, namely, an epistemology of love. As Shippee (2010) worked in her contemplative musical practice to teach a way of being-being with music and being with oneself and others (p. 80).

Therefore, spirituality is meant for the sense of self related to a broader community. Bosackia, Elliott, Akseer, and Bajovic (2010) conducted a study on Canadian children's sense of self and media habits to conclude that younger children report more issues of spirituality than older children regarding social activities of churchgoing or the reading preferences of their mothers, and solitary activities of listening to music or book-reading. Their suggestion targets the media to promote greater religious awareness in children and what Vessey (2001) indicated as an acceptance of religion-cultural diversity.

\section{Moral Education}

Giesinger (2012) attributed Kant's (1803/2007) account of discipline in moral education to the assumption of evil within human beings. According to Kant, in the process of moralization, the child must be cared for, disciplined, cultivated, and civilized. The educator is responsible for extracting moral reasoning from the child, instead of carrying knowledge. As globalization expedites the social process of diversification of ethnicity, culture, and religion, moral education faces challenges in diversity because of the influx of values. Dawidowicz (2003) evaluated moral education in schools in Utah's religion-based society to raise concerns for the evolving behaviors of students because of their expanding exposure to new ideas as a result of immigrant influxes. Utah's homogenous religious background has been upheld for over 100 years, with the Church of Jesus Christ of Latter-day Saints holding a strict moral code that is reinforced in families and schools. With demographic changes, a growing number of non-seminary attendees locally developed morality programs, such as the Community of Caring, which was incorporated with active peer tutoring and conflict mediation components until federal funding ended this program. The Dawidowicz's (2003) study concluded that moral education outside a seminary environment in undiversified areas remains passive, because teachers do not instruct morality actively.

Tirri (2011) reviewed research on moral judgment by Yussen (1977), Colangelo (1982), and Tirri (1996), who found a recurring focus on interpersonal relations among adolescents, to compare the moral dilemmas and highlight the issue of real-life dilemmas vs. hypothetical dilemmas. Koh (2012) described Kohlberg's (1958) theory of moral development to underscore the empirical approach to a universal ethical morality, in contrast to ethical relativism or the debating gap between moral judgment and moral action. Her Singapore study, which she conducted to assess the motivational regulations of adolescent students toward civics and moral education 
(CME), found the student participants showed a moderate degree of self-determined motivation in CME, but a high correlation between identified regulation and intrinsic motivation suggested opportunities for choice and ownership of their moral learning. Citing Berkowitz and Bier's (2007) finding, Koh (2012) concluded that an effective CME attempts to be engaging and relevant to students to include professional development, interactive pedagogical strategies, explicit focus on ethics or character, social and emotional competencies training, behavioral management strategies, elements of community service, and service learning (p. 96).

Tirri (2011) presented case studies to highlight the component of moral sensitivity with Finnish gifted students and Finnish Academic Olympics. Referring to the larger standard deviations with gifted students reported in the moral judgment study (Räsänen, Tirri, \& Nokelainen, 2006) and the moral reasoning study (Narvaez, 1993), Tirri (2011) concluded the qualitative differences in the moral reasoning of gifted adolescents as well as the need to nurture moral motivation and moral sensitivity to make responsible moral judgments for moral dilemmas. An earlier proposition by Koro-Ljunberg and Tirri (2002) described a concept of ethics of empowerment to relate values and beliefs to academic motivation, self-image, and the academic work culture.

Park, Kjervik, Crandell, and Oermann (2012) investigated the moral sensitivity and reasoning of South Korean nursing students and conclude the necessity of ethics content to improve moral sensitivity and reasoning for principled thinking. With a comparative review of studies reporting the changes in moral reasoning patterns between 1994 and 2007 in the South Korean population, the researchers assumed the impact of social and cultural changes in South Korean society, similar to Utah's cultural change and adolescent exposure to multiple moral choices in the Dawidowicz's study (2003).

\section{Repentance}

Hackney (2010) proposed penitence to be featured as a positive character strength in Christian positive psychology. Teece (2008) supported Hick’s (1983) concept of a "soteriological structure” to illustrate human nature, recognizing that every religion had different assumptions of the human spiritual defect, the spiritual path of transformation, and the goal of spiritual transformation. Similar to Hackney's (2010) statement of penitence as vital to growth, Buddhist repentance emphasized the ultimate goal of living with moral decency in that the practice of ritual confession and repentance ${ }^{2}$ was essential to release the individual from bad attitudes to achieve the level of Bodhisattva (Konior, 2010).

Murray-Swank, McConnell, and Pargament (2007) reviewed Dumoulin's (1967) description of the Text of Repentance $^{3}$ in sangha rituals from the Mahayanist tradition, and the American Buddhist, nun Pema Chodron's (1994) description of the four-stage process of confession. They concluded that reconciliation in Buddhism was linked to turning away from the toxic processes of the mind (e.g., greed and anger, which lead to suffering), whereas Judeo-Christianity considers confession to be a return to God. Yeung and Chow (2010) examined the religiosity of Hong Kong Buddhist adolescents. Regarding participation in religious rituals, the adolescents rarely participated in Buddhist religious rituals other than in school assemblies for Buddha's bathing ceremony on Buddha's birthday. Those who participated in a voluntary repentance rite held in a Buddhist temple seemed not to find much meaning in such a rite.

Based on the review of repentance in religious studies, the functions of repentance are seen as a personal evaluation of harm-doing and the harm-doer. Murray-Swank, McConnell, and Pargament (2007) supported the

\footnotetext{
2 The Chinese mandarin translation for the practice of ritual confession and repentance is "changhuei."

3 E. Zurcher's (2004, as cited in Konior, 2010) review to verify the first historical changhuei text by Master Tao-an (321-85 A.D.)
} 
psychiatrist Carl Jung's (1961) stance that valuing confession as an act of seeking social connection to be given a readmission of the lost sheep into the human community (p. 192). Dharma Master Cheng Yen, the founder of the Tzu Chi Education Mission, interpreted repentance as water cleansing the filth, a metaphor eliminating the three obstacles of affliction, unwholesome action, and karmic retribution (Tzu Chi Foundation, 2011):

Repentance cleanses us. In our daily life, when something becomes dirty, we use water to clean it.... To clean the impurities in our hearts, however, we need the water of Dharma. The Dharma can cleanse the afflictions and ignorance in our mind and it can remove the source of unwholesome actions, which create negative karma.

At the start of 2011, Master Cheng Yen urged her followers to join book clubs and study the Water Repentance sutra to reflect on their karma and repent from their bad habits. During August 2011, more than 30,000 Tzu Chi volunteers in Taiwan held the sutra adaptation of the Water Repentance text in the modern form of theatrical sketches, song, and sign language. This study explores the impact of a subsequent sutra adaptation process from October 2011 to March 2012 on college students at the TCCT.

\section{Methods}

This study was guided by the framework of moral education and focuses on the reflections of technical college students in the BSA experience. In addition to the on-site observations of BSA, 25 reflection journals (RJs) postings were retrieved from the school Web page from March to June in 2012. We recruited eight nursing students (three men and five women) in November for an interview, where they could share their reflections after the BSA. Among them, one female student of the RJ was posted on the school Web page. The total number of student participants from the TCCT in the 2012 BSA is 176.

Of the 25 RJs, 10 were from students from the five-year nursing program (equivalent to Grades 10 to 12), six were from nursing college students from the upper-division program, and nine were from baccalaureate students of health administration, accounting information, and electronic engineering. The other eight students who participated in semi-structured interviews (SIs) were all nursing majors from the five-year program. With one over-lapping student, the total number of participants in the study was 32. For those who clearly identified themselves as Tzu Chi Collegiate youths, Tzu Chi family ${ }^{4}$, or Tzu Chi-related clubs were coded TC. For those who clearly identified themselves as Catholic or Christian or other religions were coded different religions (DR), while for those who did not identify themselves were coded UC. Table 1 lists the background information of the 32 students.

Table 1

Student Background

\begin{tabular}{lclll}
\hline Background & TC & DR & UC & Total \\
\hline Number of RJ students & 11 & 3 & 11 & 24 \\
Number of SI students & 4 & 2 & 1 & 7 \\
Number of over-lapping & 1 & 0 & 0 & 1 \\
\hline
\end{tabular}

Using the code categories to reduce and refine the recurring ideas from the RJs and interview transcripts, we found three themes related to spiritual education as follow:

1. The stage performance of the BSA was perceived as a cooperative quasi-moral action;

\footnotetext{
${ }^{4}$ Tzu Chi family is a metaphor describing the extended family composed of Dharma Master Cheng Yen, Jing Xi monastic practitioners, Tzu Chi volunteers, and Tzu Chi staff.
} 
2. The social climate of the BSA was a hidden curriculum of collaborative moral teaching;

3. The BSA experience prompted moral reflections of action, speech, and thought.

\section{Results}

\section{Cooperative Quasi-Moral Action}

The major motif for both the RJ and SI students to voluntarily attend the BSA was the stage performance. For TC students, they understood the rationale of the BSA to promote vegetarian fasting and moral reflections, but only one student from the RJ cohort had participated in one BSA presentation in 2011 and it was with her father. For the majority of DR and UC students, they considered it as a stage performance to celebrate the 45th anniversary of Tzu Chi Missions:

I learned about the gathering without much knowledge of its meaning but a little understanding of a prayer service through stage performance. (RJNT123)

I was impressed by the touching scenes of the BSA film documenting the gatherings in Kaohsiung and Taipei. I was moved by the collective beauty of the stage performance, which pushed me to start inviting more classmates to participate. (RJNT154)

I was so attracted by the concentrative look of the Tzu Chi volunteers. Both male and female participants revealed a serene disposition. I was astonished and so moved. (RJNT218)

I learned about the stage performance involving the professional artists of modern dance, Chinese opera artists, and Taiwanese opera artists, which was a rare chance to showcase the work on the same stage with these professional artists. (RJNT2410)

I freaked and was covered with goose bumps when I watched the rehearsal from the audience section. I cannot believe they did it so harmoniously. I suddenly regretted that I have not taken the chance of signing up. Later, I hung around to watch them practice and was coaxed into joining the backup performers. (RJNT2511)

Hence, the collective unity of body movement and singing volume from the BSA film or the on-site rehearsal captured the college students' attention, because the performance was a cooperative act of professional artists and volunteers from the Tzu Chi Education Mission, including the staff and students. It was different from the common performance in the number of participants, variety of performing arts, and religious background. For this study, three-fifths DR students commented on their motivation to join the BSA:

I always remember Master Cheng Yen saying, Tzu Chi (Missions) transcends religions and ethnicities. The Bible verse Psalms 66:20 reads, "Blessed be God, Who hath not turned away my prayer, nor his loving kindness from me." (RJNB051)

I deeply believe that preaching under the name of Jesus Christ is to teach people to be pious and sincere, and to transform evil into good. Is not the BSA doing the same thing? Therefore, I believe that my dearest God permits me to communicate this simple mindset to the public through the BSA. (RJNB202)

I regarded the BSA as an action to promote the practice of good deeds and prayer service for victims. (SINB4007)

My understanding of the BSA is that it is meant for praying for peace in the world.... And I was so moved by the scene of saluting the Great Teacher of humans and heavenly beings.... Everyone bowed to show salutations and was so humble and full of gratitude. I was deeply moved. (SINB4007)

The DR students' feelings of being connected to the school or Dharma Master Cheng Yen, or to the world, revealed a non-discriminative sense of good to voice "the loving kindness" from their beliefs. It is a secure feeling from their belief that they feel not only close to the morale of the BSA, but also a collective work of moral action across religions. 
All the BSA participants must vow to be vegetarians for 108 days during the time. Although the majority of BSA participants, including teachers, were not vegetarian, the students expressed their determination to keep the vow:

It was the festival of the Chinese Lunar New Year. You can imagine how much food, especially meat dishes, was being prepared. My family disagreed with my decision to partake in vegetarian fasting, but I insisted. I must because evil doings, conditions, and retribution will lead to reincarnation. (SINB5508)

I was impressed by the lines "There must be reasons to live for each sentient being. We all live in the same world. The heavenly beings cherish every single life as virtue. There is no reason to kill any living creature.” I am an aboriginal descendent. I was brought up to eat meat with no reflections on the act of killing animals. After participating in the BSA, I suddenly realized how cruel I was to have harmed so many animals' lives. I must repent on the wrong act sincerely and piously. (RJNB263)

Instead of blaming or scolding, the singing and signing communicated a message of compassion to urge the adoption of vegetarian fasting as a token of blessing. The lines did not indicate that it was Buddhist doctrine not to kill animals for food, but referred instead to the heavenly virtue to respect any life form. Therefore, the participants' moral reasoning and moral sensitivity were enhanced by the repeated practice of singing and signing. Singing and signing served as gentle reminders to keep the vow of vegetarian fasting, which gradually transformed the performance into a cooperative action to be vegetarian, with collective efforts across religions and social backgrounds. The 108-day vegetarian fasting was set up as a benchmark to join the BSA, approximating a quasi-moral action to highlight the scheduled stage performance in the near future.

\section{A Hidden Curriculum of Collaborative Moral Teaching}

The commonly expressed recurring sentiment in the $25 \mathrm{RJ}$ is the acknowledgment of the devoted teaching of Tzu Chi volunteers on-site and the snacks provided by Tzu Chi volunteers. They felt welcomed by the Tzu Chi family that they could ease their lack of comfort because of the unfamiliar lyrics, signing, and dancing, because the volunteers never showed impatience for repeated instruction:

Tzu Chi aunties ${ }^{5}$ would correct our error of body movement without showing any begrudging or anger. I have never seen them become upset with our imperfect performance. They constantly have a smile. What a wonderful group of lovely mothers.... We do not have to worry about the meals, because the Tzu Chi uncles and aunties prepare the food for breakfast, lunch, and dinner, and even tea breaks. It is a close feeling in an extended family, so much akin to parents being concerned with their children growing hungry after practice. (RJNT165)

I really want to say thank you to the Yi-Der mothers ${ }^{6}$ who had been patiently accompanying us for the series of drills and rehearsals, no matter how late we had to stay up. There are the sisters from the Humanities Office ${ }^{7}$ including the President and the teachers along the way. (RJNT229)

I would like to thank the goodwill ambassadors ${ }^{8}$ who allowed me to stand on the stage together to perform an episode at the year-end blessing ceremony.... And I thank the classmates who had been recruited through my invitation to join the BSA in the later phase that I no longer felt alone. I must thank the Tzu Chi aunties and uncles who had been teaching us meticulously, so that we could pass the evaluation by Auntie Tzu-Yueh ${ }^{9}$. (RJTC117)

\footnotetext{
${ }^{5}$ A nickname for female Tzu Chi volunteers who had arranged their hair buns in a manner similar to that of a mother or aunt.

${ }^{6}$ Yi-Der mothers and Tzu-Cheng fathers are the commissioners designated by Dharma Master Cheng Yen as role models of Tzu Chi students for monthly functions on campus and building rapports with the students' natural families.

7 Tzu Chi Humanities Office is a special unit in Tzu Chi schools to promote humanities education and activities.

${ }^{8}$ Goodwill Ambassadors are recruited by the Tzu Chi Humanities Office at the TCCT to promote voluntary humanities services of visiting nursing homes and participating in the international exchange program in Malaysia. Due to the limited number of participants being on the stage, so Goodwill Ambassadors yielded the opportunity to those who were the first time participants in the event.

${ }_{9}$ Auntie Tzu-Yueh is the general choreographer of the BSA, who attends the BSA on a regular basis to evaluate the performance.
} 
To the RJ students, the tiring practices are worth their efforts, because they were not alone, but accompanied by a group of classmates, friends, teachers, and Tzu Chi volunteers. It is a collective memory of repeated corrections and evaluations to showcase the best work. The social climate is different from the classroom atmosphere, because everyone on-site is welcomed and valued. The morality of caring is modeled through the Tzu Chi volunteers' repeated demonstration of singing and signing. Teachers on-site also looked up to the Tzu Chi volunteers' model that the students accordingly yielded to the collective discipline and modified their body movements and behaviors. One RJ student recalled a vignette of celebrating her homeroom teacher's birthday. They had been waiting without the teacher. When the teacher finally showed, they realized that she had returned from a BSA rehearsal. She shared her consideration to give up the BSA, because she could not find enough time to practice. The teacher smiled and replied, "Hang in there! You can make it.” Thus, she suddenly realized the significance of the BSA and decided to rejoin:

I was particularly moved by the scene of the teachers also showing humility and piety, singing out loud, and signing mindfully in the BSA, and I fully respect their uprightness and sincerity. (RJNT031)

The SI students were interviewed to express their recollection of the BSA. They also participated in a short episode of BSA in the core course of Tzu Chi Humanities (TCH) in early November. The social climate of the TCH course was entirely different from that of the BSA in March 2012, because it was a required component of the course grade. They understood that their classmates could not capture the touching sentiment of the BSA and that they were there more as an obligation to fulfill the course requirement. When asked whether it was necessary to integrate the BSA vignette to the TCH course, they all agreed with a similar attitude. When the BSA episode was integrated, they had the opportunity to share their understanding and learning outcome with their classmates, and they experience a passing on of a good moral lesson. In this manner, they were more akin to teaching assistants of moral education. All SI students mentioned the feeling of "being together" (with other students and teachers), and two of them commented on the scene 12 making vows after repenting of Act IV. The obstacles of karmic retribution, which was performed by the teachers of the six Tzu Chi schools:

I felt the goose bumps when I heard the teachers' singing and their unified signing. It was beautiful and touching. (SITC2302)

Although I was not on stage but knelt looking up at the scene from the side as they performed as the waves of the sea, I felt that I was pushing the dharma vessel to sail across ${ }^{10}$. (SITC6204)

I just feel unified with the vessel. The teachers are singing and signing on the stage that everyone on-site is on the same vessel with the teachers. (SITC5806)

The vessel image is a metaphor of vows to transform the suffering into a blessing through correct ways of living; for instance, "Harbor no thoughts of killing, and help all creatures coexist in harmony," "mitigate disasters and epidemics, so that people will not suffer from pain, illness, and loss," or "help provide abundant supplies of food and clothing, so that people will not suffer from starvation and cold," which is the moral or the morality of the BSA to bring peace to the world. The collective efforts to present the vessel also signified the collaborative moral teaching invisibly situated within harmonious singing and signing.

\section{Moral Reflections of Action, Speech, and Thought}

The primary qualification to become a BSA participant is to partake in vegetarian fasting for 108 days as a

10 This student's RJ was posted on the school Web page. She was the overlapping participant in the two cohorts of RJ and SI. 
token of sincerity to curb the appetite for meat for praying blessing worldwide. Instead of verbally expressing repentance for the meat diet, the participants practiced vegetarian fasting to express their compassion. The repentance contents of the 24 RJs were categorized into four issues: vices of speech, vulnerability, meat diet, and general description, whereas the eight SIs were categorized into three issues: vices of speech, parental relationship, and jealousy (see Table 2).

Table 2

Repentance Issues

\begin{tabular}{lllllll}
\hline & Vices of speech & Vulnerability & Meat diet & Parental relationship & Jealousy & General description \\
\hline RJ Students & 0 & 6 & 4 & 0 & 0 & 7 \\
SI Students & 7 & 0 & 0 & 2 & 1 & 0 \\
\hline
\end{tabular}

Two phenomena arose from the two cohorts. The first is that vices of speech were openly confessed in both contexts. The second is that dependence on the meat diet was naturally confessed by the RJ students, but none of the SI students were determined to partake in vegetarian fasting again. They all recognized the necessity of the vegetarian diet and tried to practice vegetarian fasting when possible, but they had not set their minds to be vegetarian for another length of time. However, they began to reflect on their behaviors and interpersonal relationships, which led to the moral reflections on vices of speech, parental relationship, and jealousy:

I would reflect on the times joking and gossiping with friends, which a high possibility of creating vices of speech. (SITC4003)

I found myself easily becoming jealous that my mind was troubled and upset. (SITC6204)

I repented for my impulsive emotions to my parents, because it is wrong of me to display impatience on my face and in my voice. I was hot-tempered and inclined to argue. (SINB6505)

I admit I had laughed at people’s mistakes or mishaps, which is not kind. (SITC5806)

Regarding the defect of vulnerability confessed by RJ students, when the public performance day was approaching, they could easily recall their initial struggles of being torn between giving up or continuing the practice:

I once envied the youths who were eating meat, and even those indulging in alcohol. Now that I have the second thought, why should I? I vowed to take up vegetarian fasting, because I do not want to harm the lives of animals to satisfy my desire to eat. What made me a Tzu Chi Collegiate youth? I became acquainted with Tzu Chi to follow the footsteps of the Venerable Dharma Master Cheng Yen. I, a youth with energy and strength, could make a difference in the world. (RJTC063)

It was the day of trying on the costume. I had been sitting in the Humanities Office for an hour thinking hard on whether I should sign up or give up. I could hear two voices speaking in my heart. One said, "Back out now. You do not have to work so hard.” The other said, "Do you really want to give up? If you give up, all the efforts will be gone. This is the only chance in your life to do the BSA. It is hard to know if there will be another." I repeated the questions again and again, and finally I chose to sign up. (RJNT072)

The BSA seemed to motivate the participating students to examine their moral defects in a gentle manner, either through the diet appetite or the indecisive nature to hold on to the principle or the moral calling. They began to identify themselves with the morality communicated through the BSA, relinquishing the worry of being different from their young peers or the fear of growing exhausted from the intensive practices. 
Similar reflections on the vices of speech were shared by one RJ student with more reconciling thoughts:

Before, I would justify my position with angry remarks or point my finger at wrongdoers.... I found myself easily irritated and lost most of my friends.... Now, I join the BSA and reflect on the mistakes and vices of speech being intertwined with justice... Dharma Master Cheng Yen’s aphorism teaches us, "Remain soft-spoken and forgiving, even when reason is on your side.” Verbal blaming creates vices of speech and harms feelings. (RJNT1806)

If not immersed in the sight of the BSA, RJNT1806 would not have had the chance to reflect on his interpersonal problems associated with vices of speech. The moral reasoning was framed within the BSA experience, which struck him hard with the concepts of bad cause, bad karma, and bad retribution.

\section{Discussion}

This paper presents the reflections of 32 students on their BSA experience. Three themes emerged as below:

1. The stage performance of the BSA was perceived as a cooperative quasi-moral action;

2. The social climate of the BSA was a hidden curriculum of collaborative moral teaching;

3. The BSA experience prompted moral reflections of action, speech, and thought.

The first theme attempts to highlight the medium of performing arts to motivate the practice of vegetarian fasting. The second theme was related to the harmonious environment that was full of morality models of caring. The third theme identified the influences of repeated singing and signing on the participants' recognition of strengths and limitations. Accordingly, these three issues are related to the theories of spirituality, morality, and repentance.

\section{Media for Moral Action}

The BSA successfully integrated music, singing, signing, dancing, and drama to lead the participants to a fuller experience of music and self (Shippee, 2010, p. 78), to the extent that the sounds and images shape the spiritual landscape and develop inner guidance. All BSA participants seemed connected with a shared motif-vegetarian fasting. Although the sutra is structured within Buddhist teachings, the music enlivens harmony, as Carr (2008) maintained, in which the music of the BSA shoulders a spiritual experience and a quasi-moral action. The BSA stage performance naturally facilitates the participating students to experience multiple ways to relate to the world in a manner similar to Greene's claim (1995, as cited in Tisdell, 2007). The students' reflections support the media function of the BSA in the high awareness of the spiritual significance of no killing for food, which is practiced in the fasting lifestyle. They supported the continued practice of the BSA experience in the humanities course, so that they could pass on the moral lessons and extend the impact of their moral action, to eventually embody the vessel symbolized in the Water Repentance text sailing across and motivating more followers to take moral action.

\section{Moral Models for Caring}

The BSA context showcases a homogeneous culture based on the shared mindset of vegetarian fasting. All participants, including the professional performing artists, catering volunteers, singing volunteers, signing volunteers, and even the technicians, must sustain the vow to fast on a vegetarian diet for 108 days. Davidowicz's (2003) observations of the changing demography of Utah's religion-based society posed challenges to traditional morality training in Utah, US. Conversely, the BSA attracted student participants of 
Tzu Chi connections, from different religions and different ethnic heritages (e.g., aboriginal ethnicity), so that the stage had been metaphysically enlarged and extended to the snack areas where the catering volunteers provided the student participants with meals and drinks. Their service communicated the best example of caring and altruistic giving, much akin to an extended family, and it was described by the RJ students in the study. It is similar to a communiqué of moral teaching by various role models through the functions of singing, signing, and catering, resonating in Koh's (2012) review of informal approaches to value education, as claimed by Sharma and Mohite (2007). Differing from the competitive sense of learning for grades in an ordinary classroom, the BSA experience was effectively associated with a harmonious environment in which good is the only choice and the end.

\section{Recognitions of Strengths and Limitations}

Both the RJ and SI students confessed their weaknesses and moral defects in their written and oral reflections. They had been immersed in the BSA context for three to six months through singing and signing. The singing and signing practices were more akin to discipline and cultivation in the process of morality development, whereas the teachers, volunteers, or peers acted similarly to caretakers to nurture their sense of security. Music, lyrics, and body movement were constantly contemplated that they came to their own moral reasoning of vices of speech, parental relationship problems, or appetite curbing for meat. This process is consistent with Kant's account of moral education in the sequence of caring, disciplining, cultivating, and civilizing (Giesinger, 2012), in which the BSA was operated as an inner dialogue to communicate the moral to participants, and eventually retrieve the inner morality from the participants. The repentance issues from the RJ and SI data showed a tendency of interpersonal relations problems for adolescents that are similar to Tirri's (2011) review of the studies by Yussen (1977), Colangelo (1982), and Tirri (1996).

\section{Conclusion and Implication}

The emerging themes indicated that the BSA experiences motivated the participating students to reflect on their weaknesses and moral defects. Through the medium of artistic presentation, the moral text had been repeatedly recited, sung, signed, and acted out in body movement. The students' expressions of being cared by constant coaching and snack services, as well as in the company of teachers, peers, and Tzu Chi volunteers, confirmed the impact of informal approaches to spiritual education and moral values across religions. The students' indication of the necessity of passing the spirit of praying for peace for the world in the humanities course justified the moral reasoning being developed.

This study is a descriptive presentation of the impact of BSA experience on college students' spirituality and morality, in light of the effect of role modeling through performing arts, good examples through coaching and catering, and a positive and harmonious environment of rehearsals and stage presentations. Two implications of the study reveal the significance of the interactive medium of performing arts to prompt moral reasoning and moral sensitivity. Firstly, the practice of vegetarian fasting seems to be modeled as a qualification to the stage performance but not performing talents, because every participant served as a living model of moral action of no killing for food and praying for peace for the world. Although most of the participating students do not continue fasting after the BSA, they manage to be vegetarians as much as possible, in contrast to their heavy meat diet before the BSA. Secondly, the repeated practice of singing and signing had been coached and accompanied by teachers, peers, and volunteers, compared to the lonely drills for academic 
evaluations, which generated a social climate of collective work of virtue. This special form of moral education through BSA experiences deserves further investigation on the pedagogical issues of discipline and cultivation.

\section{References}

Berkowitz, M. W., \& Bier M. C. (2007). What works in character education? Journal of Research in Character Education, 5(1), 29-48.

Bosackia, S., Elliott, A., Akseer, S., \& Bajovic, M. (2010). The spiritual component of children’s lives: The role of media. British Journal of Religious Education, 32(1), 49-61.

Carr, D. (2008). Music, spirituality, and education. Journal of Aesthetic Education, 42(1), 16-29.

Chodron, P. (1994). Start where you are: A guide to compassionate living. Boston, M.A.: Shambhala.

Colangelo, N. (1982). Characteristics of moral problems as formulated by gifted adolescents. Journal of Moral Education, 11, 219-232.

Dawidowicz, P. (2003). Teaching morality in schools in Utah's religion-based society. Journal of Moral Education, 32(3), 275-289.

Dumoulin, H. (1967). The consciousness of guilt and the practice of confession in Japanese Buddhism. In E. E. Urbach, R. J. Awi Werblowsky, \& C. H. Wirszubuski (Eds.), Studies in mysticism and religion presented to Gersham G. Scholem on seventieth birthday (pp. 117-129). Jersualem, the Hebrew University: Magnes Press.

Elkins, D. N., Hedstrom, L. J., Hughes, L. L., Leaf, J. A., \& Saunders, C. (1988). Toward a humanistic-phenomenological spirituality. Journal of Humanistic Psychology, 28(4), 5-18.

Fowler, J. (1981). Stages of faith: The psychology of human development. San Francisco: Harper and Row.

Giesinger, J. (2012). Kant's account of moral education. Educational Philosophy \& Theory, 44(7), 775-786.

Greene, M. (1995). Releasing the imagination: Essays on education, the arts, and social change. San Francisco: Jossey-Bass.

Hackney, C. H. (2010). Sanctification as a source of theological guidance in the construction of a Christian positive psychology. Journal of Psychology \& Christianity, 29(3), 195-207.

Harrison, R. K. (Ed.). (1987). Encyclopedia of biblical and Christian ethic (Vol. 26, pp. 651-673). Nashville, T.N.: Thomas Nelson Publishers.

Hick, J. (1983). The second Christianity. London: SCM Press.

Jung, C. G. (1961). The theory of psychoanalysis, collected works (Vol. 4). New York, N.Y.: Pantheon Books.

Kant, I. (1803/2007). Lectures on pedagogy. In G. Zöller, \& R. B. Louden (Eds), Anthropology, history, and education: The Cambridge edition of the works of Immanuel Kant in translation. Cambridge: Cambridge University Press.

Koh, C. (2012). Moral development and student motivation in moral education: A Singapore study. Australian Journal of Education (ACER Press), 56(1), 83-101.

Kohlberg, L. (1958). The development of modes of moral thinking and choice in the years 10-16 (Unpublished Ph.D. thesis, University of Chicago).

Konior, J. (2010). Confession rituals and the philosophy of forgiveness in Asian religions and Christianity. Forum Philosophicum: International Journal for Philosophy, 15(1), 91-102.

Koro-Ljungberg, M., \& Tirri, K. (2002). Beliefs and values of successful scientists. Journal of Beliefs and Values, 23(2), 141-155.

Lerner, M. (2000). Spirit matters: Global healing and the wisdom of the soul. Charlottesville, V.A.: Hampton Roads.

Miller, L., \& Athan, A. (2007). Spiritual awareness pedagogy: The classroom as spiritual reality. International Journal of Children's Spirituality, 12(1), 17-35.

Mische, P. (1994). Religion and world order. In Proceedings of the symposium on religion and global governance. Washington, D.C.. (ED 398149)

Murray-Swank, A. B., McConnell, K. M., \& Pargament, K. I. (2007). Understanding spiritual confession: A review and theoretical synthesis. Mental Health, Religion \& Culture, 10(3), 275-291

Narvaez, D. (1993). High achieving students and moral judgment. Journal for the Education of the Gifted, 16, 268-279.

Palazzini, P. (Ed.). (1962). Dictionary of moral theology. (H. J. Yannone, Trans.). Westminster, M.D.: The Newman Press.

Palmer, A. (1995). Music education and spirituality: A philosophical exploration. Philosophy of Music Education Review, 3(2), 91-106.

Palmer, P. (1993). The violence of our knowledge: Toward a spirituality of higher education. Retrieved June 6, 2008, from http://www.21learn.org/arch/articles/palmer_spirituality.html 
Park, M., Kjervik, D., Crandell, J., \& Oermann, M. (2012). The relationship of ethics education to moral sensitivity and moral reasoning skills of nursing students. Nursing Ethics, 19(4), 568-580.

Parks, S. (2000). Big questions, worthy dreams. San Francisco: Jossey-Bass.

Rahner, K. (Ed.). (1969). Sacramentum mundi: An encyclopedia of theology (Vol. 4). New York, N.Y.: Herder and Herder.

Räsänen, A., Tirri, K., \& Nokelainen, P. (2006). The moral and religious reasoning of gifted adolescence. In K. Tirri (Ed.), Nordic perspectives on religion, spirituality, and identity (pp. 97-111). Helsinki, Finland: University of Helsinki.

Rendon, L. (2000). Academics of the heart: Reconnecting the scientific mind with the spirit's artistry. The Review of Higher Education, 24(1), 1-13.

Sharma, D., \& Mohite, P. (2007). Teachers’ perceptions of values education for children. In C. Tan, \& K. Chong (Eds.), Critical perspectives on values education in Asia (pp. 30-49). Singapore: Prentice Hall, Pearson Education South Asia.

Shippee, M. (2010). The sound of starting where you are: Contemplative practice and music pedagogy. New Directions of Community Colleges, 151, 77-89.

Smith, D. (1994). Toward developing a theory of spirituality. The Journal of Rogerian Nursing Science, 2(1). Retrieved November 25, 2012, from http://www.biomedsearch.com/article/Toward-developing-theory-spirituality/161555254.html

Smith, W. L., \& Zhang, P. (2011). Religiousness and spirituality: An analysis of a practice-oriented retreat. Sociological Viewpoints, 27, 57-75.

Teece, G. (2008). Learning from religions as skilful means: A contribution to the debate about the nature of religious education. British Journal of Religious Education, 30(3), 187-198.

Tirri, K. (1996). The themes of moral dilemmas formulated by preadolescents. Education Resources Information Center. (Resources in Education, ED 399046)

Tirri, K. (2011). Combining excellence and ethics: Implications for moral education for the gifted. Roeper Review, 33(1), 59-64.

Tisdell, E. (2006). Spirituality, cultural identity, and epistemology in culturally responsive teaching in higher education. Multicultural Perspectives, 8(3), 19-25.

Tisdell, E. (2007). In the new millennium: The role of spirituality and the cultural imagination in dealing with diversity and equity in the higher education classroom. Teachers College Record, 109(3), 531-560.

Tzu Chi Foundation. (2011, May). Over 500 volunteers make first performance of Buddhist sutra. Retrieved November 27, 2012, from http://www.tw.tzuchi.org/en/index.php?option=com_content\&view=article\&id=796\%3Aover-500-volunteers-makefirst -performance-of-Buddhist-sutra\&catid=1\%3Ataiwan\&Itemid=263\&lang=en

Vessey, D. (2001). Hey didily-do, neighoreenos: Ned Flanders and neighborly love. In V. David (Ed.), The Simpsons and philosophy: The D'oh of Homer (pp. 202-214). Chicago, I.L.: Open Court Publishing Company.

Yeung, G. K., \& Chow, W. (2010). To take up your own responsibility: The religiosity of Buddhist adolescents in Hong Kong. International Journal of Children's Spirituality, 15(1), 5-23.

Yussen, S. (1977). Characteristics of moral dilemmas written by adolescents. Developmental Psychology, 13, 162-163.

Zajonc, A. (2006). Love and knowledge: Recovering the heart of learning through contemplation. Teachers College Record, 108(9), 1742-1759.

Zinnbauer, B., Pargament, K., \& Scott, A. (1999). The emerging meanings of religiousness and spirituality: Problems and prospects. Journal of Personality, 67, 889-919

Zürcher, E. (2004, June). Buddhist changhui and Christian confession in 17th century China. In Ritual Workshop Sinologie (p. 10). Leuven: Katholoieke Universiteit. 